\title{
COVID-19 quarantine stressors and management among Lebanese students: a qualitative study
}

\author{
Mirna Fawaz ${ }^{1}$ (1) $\cdot$ Mohamad Al Nakhal $^{1} \cdot$ Mohammad Itani $^{1}$ \\ Accepted: 16 December 2020 / Published online: 3 January 2021 \\ (C) The Author(s), under exclusive licence to Springer Science+Business Media, LLC part of Springer Nature 2021
}

\begin{abstract}
The aim of this research paper is to examine the current situation, emotional reactions of university students and their coping mechanisms during and after the COVID-19 quarantine. The study was undertaken in a major higher education institution in Lebanon. An exploratory qualitative research design was adopted. A phenomenological qualitative method was employed where, semi-structured interviews were carried out among 20 university students during and 3 months after release from quarantine. The qualitative analysis have revealed 5 themes during quarantine period namely "Concerns regarding learning and evaluation methods", "Overwhelming load", "Dealing with technical difficulties", "Confinement", and "Coping with problems", in addition to 3 themes after the quarantine period namely "Relief of academic stress", "Fear of becoming infected and jeopardizing family health", "Stigma of being infected". The quarantine has inflicted multiple psychological challenges among university students, which should be highlighted and mediated by higher education institution in order to support the students' learning and their academic achievement.
\end{abstract}

Keywords Psychosocial effects $\cdot$ Quarantined $\cdot$ COVID-19 $\cdot$ University students $\cdot$ Stress and coping

\section{Introduction}

Since November 2019, the novel Coronavirus have started to develop into a worldwide health phenomenon, afflicting diverse communities, and imposing panic among millions of people. The rapid spread of COVID-19 has incentivized governments around the world including Lebanon to take extreme actions such as imposing social quarantine, mandatory curfew, closing the airport, and closing private and public institutions including schools, colleges and universities (Bizri et al. 2020). These measures have accentuated the daily life demands on Lebanese citizens especially in the light of the burdensome economic crisis, where recent studies have shown that $40 \%$ of the population has become under the poverty line

Mirna Fawaz

mirna.fawaz@bau.edu.lb

Mohamad Al Nakhal

mohamad.nakha197@gmail.com

Mohammad Itani

mohammad.itani@bau.edu.lb

1 Nursing Department, Faculty of Health Sciences, Beirut Arab University, Tareek Al Jadida, Afeef Al Tiba, Beirut 1105, Lebanon
(ESCWA 2020). These numbers that are expected to rise upon the COVID-19 embargo as many of the Lebanese people depend on day to day income to provide for their families' needs and their children's education.

Upon the fast propagation of COVID-19, serious illness, mortality in complicated cases and no effective treatment, it presents an immense danger to the wellbeing of mankind, and it therefore has a significant effect on the general population's psychological health, afflicting individuals with a variety of affective problems (Gao et al. 2020). The outbreak of SARS in China 17 years ago also gave rise to pervasive serious worries and intensified mental situations (Gardner and Moallef 2015). Therefore we should expect that the COVID19 pandemic will contribute to psychosocial responses such as agitation, depressed moods, and apprehension that can contribute to psychiatric problems such as PTSD, panic attacks and suicidal attempts. Psychological apprehension is more terrifying than illness itself (Huang et al. 2020). While communicable diseases give rise to a broad variety of emotional reactions, not everybody display similar degrees of emotional influences (Khalid et al. 2016). In fact, the sentiments were correlated with the usage of different coping techniques (Chen et al. 2018). In fact, adults who show more frustration and apprehension tend to use active-oriented mechanisms of coping such as expressing concerns, whereas those who are depressed are more 
inclined to use non-active coping mechanisms such as ignoring or embracing concerns. In essence, usage of coping techniques effectively can help in handling challenging situations and decreases harmful emotions (Heffer and Willoughby 2017). Nevertheless, there is no definite pattern of the association between emotional reactions and coping mechanisms and the interaction is not necessarily consistent.

The psychological burden of COVID-19 quarantine has been on the rise among Lebanese families, where both parents and students have to learn how to conform and adapt with the pressing reality. Psychological determinants linked to quarantine included the period of the quarantine, inaccurate knowledge, lacking resources, social and family separation, and risk of contamination, financial strain and stigma. Living under quarantine can be disturbing, especially for children and young adults who are often motivated and used to urban lifestyle (Brooks et al. 2020).

The learning process of 1.37 billion students have been impeded in over 130 states due to school and university suspensions. The Lebanese academic system in its entirety have abruptly shifted to using the virtual clouds, databases, interactive platforms in order to deliver information to the students who have to abide by the imposed quarantine, and at the same time keep up with their education. In Lebanon, e-learning has been introduced slightly, through a national academic reform process, where various universities have employed multiple online platforms such as Moodle, Blackboard and Lucien in order to create a communication portal with the students, as well as deliver online courses and blended learning. However, the sudden shift of the whole academic process to the clouds has certainly created a shock, where students have to face immense challenges that are associated with e-learning especially in majors that depend on practical aspects rather than theoretical ones. Recently, Lebanon's academic suspension has been postponed until further notification, including the cancelation of the final exams for primary and intermediate students. In addition, pandemics can impose substantial psychological burden, which can contribute to negative consequences on students' education and holistic psychological wellbeing (Al-Rabiaah et al. 2020).

Multitude of research analyzed the anxiety and mental distress resulting after such situations, but does not represent the real stress respondents feel during the incident itself. Several reports discussed related concerns among healthcare staff and citizens; nevertheless, only a paucity of research examine the psychological burden of the COVID-19 epidemic amongst university students (Husky et al. 2020; Van Nguyen et al. 2020). Therefore, the correlation between the coping mechanisms of the university students and the affective reactions during a pandemic such as COVID-19 needs to be explained further. In addition, to our awareness the impact of COVID-19 on college emotional reactions and coping mechanisms has not been evaluated. On this basis, the aim of this research paper is to examine the current situation, emotional reactions of university students and their coping mechanisms during the COVID-19 pandemic.

\section{Methods}

\section{Research Design}

This research paper have employed an exploratory qualitative research design in order to acquire a thorough and clear picture of the stressors and coping mechanisms among Lebanese students during and after the COVID-19 quarantine. The qualitative method that has been adopted into this research is the phenomenological method, which is based on the perspectives and insights of the participants to describe the occurring phenomenon. Colaizzi's phenomenological approach focuses on participants 'perceptions and emotions, and seeks similar characteristics among research subjects rather than individual features (Shosha 2012). The epistemological approach that supports this study is an objective one. Epistemology is an inference that we build regarding the type of knowledge (Richards 2003) and how we interpret the world (Crotty 1998) and think critically of it. Simply stated, it is nature and form, the way information is gained and conveyed. As far as ontological and epistemological practices are concerned, two distinct philosophies exist: Objectivism/Positivism and Interpretivisim/Constructivism. Information is perceived as hard, observable, empirical, stable and value-free from a positivist/objectivist viewpoint, where an investigator separates himself from the investigation so as to simply analyze, calculate and evaluate, etc., with no effect on the results. In contrast, from an interpretivist and constructivist point of view, information is seen as contextual, intimate, special and dynamic where researchers are concerned with the participants. While the previous is highly connected with the practice of quantitative analysis, the latter is connected to the tradition of qualitative design. The ontological presumption thus affects our epistemological tendency, which in turn determines the process and nature of science. The analytical methods of our research are framed by the interpretivist/ constructivist tradition, which is phenomenological qualitative architecture (Schmitt 2017).

\section{Study Subjects}

A purposive sampling technique was used (Etikan et al. 2016) and have recruited 20 undergraduate students from a major higher education institution in Lebanon. The students eligible to participate in the study were specified to be of Lebanese nationality, are actively enrolled in a bachelor program as their first higher education major and have not been double majoring in any other field, have not be 
enrolled in the bridge program, have not transferred from another university, and are in their senior year, thus they have got used to the university system.

\section{Recruitment and Data Collection}

The students were contacted via email, as access to the pool of university webmails have been granted to the researchers, where students have received a general invitation to participate in the research, in addition to an explanation of the research purpose and were required to send back a written informed consent if they were willing to participate. After recruitment of the study respondents, they were invited to participate in hour long semi-structures interviews on two occasions; during the quarantine period and 3 months after the release from quarantine, where the students have returned to the university premises to compensate for certain courses.

\section{Interviews}

The three investigators carried out the interviews, where they have kept on conducting interviews until data saturation was reached. On the first occasion and due to the imposed quarantine, 17 interviews were carried out through facetime while 3 of the students were accessible to take part in face-to-face interviews while observing the required measures for physical distancing and infection prevention and control. On the second occasion, 20 interviews with the same students that have previously participated in the semi-structured interviews have been conducted where one on one interviews have taken place in a classroom at the university. A suitable timing for the interviews was agreed upon with each individual especially in light of their packed academic schedules, in order for them to be available and to provide reliable accounts of their experiences. The researchers alternated in conducting the interviews in order to avoid a moderator's dominance from occurring. Thus, during quarantine the researchers have asked the students: "How do you describe your experience as a university student in quarantine?", "How is quarantine affecting your learning experience?", "What are the sources of stress you are facing during quarantine and how are you dealing with them?" After quarantine the researchers asked one question, "What are the sources of stress you are currently facing and were any of the previous stressors relieved?"

\section{Data Analysis}

The students were informed that the facetime interviews will be screen-recorded and the face-to-face interviews will be tape-recorded in order to keep record of the data and use them in data analysis. The students accounts of their experiences were transcribed into English and were evaluated through an inductive thematic content analysis, which comprised of narrating the verbatim provided by the participants, open text labeling, and producing categories and developing the themes (Corwin and Clemens 2020; Hand 2013). The analysis was conducted by each researcher on their own, and after that the investigators have convened and held a discussion of the results until reached an agreement on the emergent findings, while making sure not to involve their personal views in the matter. The verbatim was narrated multiple times in order to acquire a profound and reliable comprehension of the students' accounts and then the quotations were assigned an expressive and reflective word which highlights the true meaning of the datum provided, and after that those words were grouped, regrouped and aggregated into qualitative themes, which were keenly evaluated by the investigators to guarantee that they are representative of the experience under study.

\section{Trustworthiness and Credibility}

In an attempt to improve the trust worthiness of the research paper and prevent biases from occurring, various procedures were carried out by the investigators in line with previous literature in the field of qualitative research (Anney 2014). Simultaneous evaluation of the data meant that the concepts developed could be investigated for a complete understanding of phenomena through parallel interviews. All investigators have used the same interview structures and the same questions were employed, and they have made sure to thorough discuss the emergent concepts and not to have any blind spots regarding any elements in the findings. Multiple quotations were used to express the research outcomes, which have offered the participants in this study a genuine voice. In addition, experts in the field of qualitative research have been consulted, where control procedure were used to double check the results. The analysis was carried out independently, and in addition to peer-checking the researchers have also used member-checking to ensure credibility and validation, where after finalizing the themes they were redirected to the participants for verification (Speziale et al. 2011). Moreover, external member-checking was also used, in order to ensure that the results are generalizable, where students having the same characteristics as those who took part in the study were asked to recognize the comparability between the emergent themes and their own experience.

\section{Ethical Considerations}

Institutional Review Board was acquired from the university from which data was collected (IRB number: ECO-R-20). All the participants have submitted written informed consent upon knowing that participation is completely voluntary and attrition from the study has no negative consequences. The students were also assured more than once that their participation 
is anonymous and that any data to be published would be unidentified.

\section{Results}

\section{Characteristics of the Respondents}

The study sample included 20 university senior students where $11(55 \%)$ were females while $9(45 \%)$ were males and the mean age of the students was 22.3 years. The students were distributed across faculties $5(25 \%)$ of the students were health sciences students $3(15 \%)$ were business administration students, $3(15 \%)$ studied law, 3 (15\%) studied arts, and 3 $(15 \%)$ were engineering students. All the participants were Lebanese and lived in the capital Beirut, and they all were from average income families.

\section{Phenomenology}

\section{During Quarantine}

The thematic data analysis has produced multiple themes which were reflective and genuine to the recollections of the students, where the main stressors were related either to the quarantine itself or to the fact that they have to continue their instruction remotely from home. The emergent themes were namely, "Concerns regarding learning and evaluation methods", "Overwhelming load", "Dealing with technical difficulties", "Confinement", and "Coping with problems".

\section{Concerns Regarding Learning and Evaluation Methods}

The students who took part in the study have expressed various worries regarding their academic achievement. Although they have appreciated the efforts being exerted by their professors, the students have voiced their concern regarding the online learning method which was imposed by national university closure due to COVID-19 quarantine. They have indicated that they are not sure whether they are grasping the material through online portals and were skeptic of the efficiency of the instruction techniques and evaluation methods. For instance, one of the students said, "I know our professors are doing their best to help us during this crisis and they have no other choice but to continue teaching us form a distance especially that we are seniors and we have to graduate, but personally I am not understanding all the concepts, especially that I tend to ask a lot of questions to clarify my confusions and online portals are quite challenging in that aspect, so it is taking me more effort and time to research and it can get frustrating at many instances... I do not know how my grades will turn out" (S6). Another student indicated, "I usually depend on the instructor's presence in the classroom to grasp the material discussed, now that we have to learn from home through online platforms it is really hard for me to understand the lectures. The professors are explaining through video tools, but with big number of students, it is not possible for me to ask a lot of questions during the livestream" (S2). In addition, another student recounted, "It is harder to study at home...not sure if I am getting all the information I need ... and when it comes to exams it is even more frustrating as we do not get to ask the professor any questions...sometimes we do not have clarity, and not even enough time to finish an exam. It is very stressful" (S17). Moreover a student voiced, "I think that online learning can be used an adjunct to instruction but being responsible of all topics that are delivered online and being tested and graded based on exclusively online learning is somehow unfair. It is the only way to learn now...I do not know if we can have extra sessions especially that I am a senior and will graduate soon hopefully... but it is indeed frustrating for both the student and the instructor I guess. I worry about if I am properly learning as well as my grades" (S11).

\section{Overwhelming Load}

Another important point that the students reported was that their instruction schedule is being very tight, and they are being overwhelmed with requirements more than when they used to physically attend the university. For example one of the students said, "At the start of the semester I have registered 18 credit hours... a challenging load to keep up with you know, but I was doing okay when we were still attending; everything was properly scheduled ...I did not know it will get this intense now. Since we started online learning almost everything started overlapping. Lots of assignments and reports to hand in...I barely have the time to do anything else" (S4). Another student also had a similar experience, "It is a lot of work. Many things to do in limited time...deadlines to meet all the time...many courses and many assignments for each course...it is getting really heavy and stressful. Online sessions are sometimes even overlapping, I'd need to skip a session to attend another one and postpone that session to watch it offline which means I can't get the full proper experience out of everything" (S9). In addition, another student recounted, "I'm always behind the laptop... my back hurts...barely seeing my parents and we are quarantined in the same house. There are loads of required assignments and discussions and reports... I do not know if I am doing well in all of them. I am even missing some deadlines and I'll have to contact the professor to ask for an extension as many required evaluations are due at the same time" (S13). Moreover, a student said, "I am always stressed... I get angry quickly as I am dealing with university requirements at all times, whether doing assignments, exams, attending online lectures...it makes me feel restricted and as if time is fleeting as I am not 
having enough time to deliver everything that is asked from me and when my family need anything I get cranky" (S19).

\section{Dealing with Technical Difficulties}

The students have indicated that dealing with technological difficulties and hindrances is a major stressor and source of frustration while they are participating in online learning during COVID-19 quarantine. One of the students reported, "The internet connection is not the best...not only in my household but I mean we have an internet problem in Lebanon. It is so stressing to learn online with such conditions. During the lectures either the connection goes down or the electricity goes off...sometimes the system itself tilts and I can barely keep up" (S20). Another student expressed the same concerns, “... the sessions are always interrupted by the terrible internet connection or by the power outage. Also the online activities that we are supposed to take part in use heavy platforms because they use video based streaming, therefore I'd need high speed internet and large amounts of megabytes; however the internet quota that we have is not enough to satisfy the needs" (S5). Also another student shared, "I do not have a laptop at home, I tried to use my phone to keep up with my online lectures but the software crashes all the time and the student data provided by the ministry expired quickly, which left me no choice but having to go to a friend's house to use his laptop ...such an inconvenience especially that it is frustrating enough that I have stay home because of the existing pandemic...so I am risking my health I guess" (S1).

\section{Confinement}

The students in this study have also conveyed that the quarantine situation is not helping with all the stress that they are dealing with from various facets whether academically, personally, or even financially. One of the students said, "The confinement that was imposed due to quarantine adds to the pressure of the whole situation. I cannot meet up with my friends to study together. I cannot go out to relieve the stress and my work has also stopped so I cannot make some money to help my family with tuition as I used to" (S15). Another student also recounted, "The embargo that was imposed by the government due to the coronavirus outbreak is essential but it is very stressful...I feel imprisoned...I can't catch a breath in the midst of the whole situation... sometimes it's like I'm running out of oxygen...it all came at once...the outbreak...the economic crisis and the university closure" (S8). In addition, a student proclaimed, "On top if the university issues, comes the outbreak...my father's work is a day to day pay job...I used to work to help out with home needs and my tuition...now both of us are confined at home, we can't make any money... we can't even take off some of the stress of the whole situation...I'm always worried about my family making ends meet ... me graduating or not..." (S16). Moreover, another student also shared a similar experience, "It's like the walls are closing in... the other day I went down to the street it was like I'm reborn....all the university stress and the family issues during these difficult times are worsened by the fact that we do not have an outlet to steam off...any stress relief will have to occur at home... same setting...you get frustrated and anxious a lot..." (S7).

\section{Coping with Problems}

The final theme emerged as the investigators asked the students about how they are dealing with these pressing circumstances. The students reported using active-oriented coping mechanisms, as they acknowledge their situation and they try to deal with it rather than just give up on it. For example one of the students said, "I try to work out when I can...it makes me feel active... alive, it changes things up you know. I look up new workouts to try when I can to relieve my stress. As for any issues I try to discuss with my advisor over the phone... I talk it out with my family ...my close friends you know, it helps...it'll pass soon" (S19). Another student also reported, "I knowledge the whole situation, I talk about my worries with my mom...she listens...learning new things to cook, watching movies when I have the time to of course, I try to do some home activities to keep sane you know" (S3). In addition, a student said, "... sometimes I shutdown from all the pressure, I can't take it no more...I stop everything...I turn on Netflix... A comedy perhaps and just laugh it out...release some stress you know...then I'd have some energy to work again" (S10). Some students also reported negative behaviors to cope with their stress, for example one of the students said, "I am smoking a lot, more than usual...the pack of cigarettes is not sufficing for one day" (S12). Another student also recounted, "I am always preparing shisha and food, not being physically active that much, I'm smoking and eating a lot even while I am studying" (S14).

\section{After Quarantine}

After the quarantine period has ended the students were called back to the university to compensate for certain courses as well as have been taking part in various related activities. Upon their return and their availability on campus the students who previously participated in the interviews were asked to take part in face to face interviews to follow up on the situation of the students and compare their stress and coping patterns to that during the quarantine period. The interviews took place approximately 3 months after the quarantine period has ended, and the thematic analysis have shown a varying picture than that which was prevalent during quarantine, where the following themes emerged, "Relief of academic stress", "Fear of 
becoming infected and jeopardizing family health", "Stigma of being infected".

\section{Relief of Academic Stress}

The students have recounted that their return to almost normal life after the quarantine period and specifically their return to campus have started to relieve their academic related stress, as they have now more control over their learning experience. For instance, one of the students proclaimed, "I truly needed direct contact with the instructors to actually learn...during quarantine I was merely lost, but now I feel less stressed regarding my learning and my grades" (S7). Another students also indicated, "I feel better now I can actually communicate with my professors rather than just talking into a glitch screen. I can actually ask questions and understand. This makes me a bit relaxed that I can follow up on my learning and objectives effectively" (S13). Another student added, "I am still stressed... But less stressed... Less concerned about university and graduating. At least now I can compartmentalize my thoughts and not just freak out about everything at once" (S3).

\section{Fear of Becoming Infected and Jeopardizing Family Health}

Another theme that the students have highlighted after the quarantine period is that the return to normal activity and the university posed a risk of infection to them and consequently to their loved ones, as they are not sure it is safe to socialize. For example one of the students said, "Since we got out of the house, I am scared that I would get coronavirus infection and get my ill mother sick...she won't handle the disease as she is diabetic and has hypertension" (S12). Another student also proclaimed, "I'm always obsessed with the idea that I will infect my family... as I don't feel safe having to go out to work and university and come back home. I am getting obsessed with the number of cases and using antiseptics all the time" (S9). Also, another student also indicated, "Since we went back to our normal routine, I have become very paranoid about any symptoms of COVID-19 infection... if I cough, if I sneezed, I directly think I am infected as I have been going out frequently to work and to uni...it is pretty scary the thought of getting ill and getting my family affected" (S2).

\section{Stigma of Being Infected}

The final theme that has been prevalent among the students post-quarantine is that people look at each other as if they are walking dangerous hotspots of infection which created a huge stigma regarding the illness. For example, one of the students said, "I got the flu, I tested negative for coronavirus, all of my friends starting treating me as if I am a walking virus, making jokes about being infected with COVID-19, they even started distancing themselves from me, it did not feel good" (S14).
Another student also testified, "I work at a hospital as a nurse and my friends and family are scared of me, and they always call me Corona, as if I am shamed to be working with patients" (S1). Also another said, "I am always hiding if I want to cough or sneeze as I know how stigmatized it is to do that in public nowadays. If you do everyone would be looking at you in a weird way...these days you can't even do a normal thing which is sneeze. They directly say you are infected" (S10).

\section{Discussion}

Lebanon is currently going through tremendous challenges from an economic crisis, to unstable political climate and most recently the COVID-19 outbreak; circumstances that are pressing on all citizens and mainly university students who are trying to build the foundations for a bright future through acquire higher education (Jaspal et al. 2020). The COVID-19 pandemic, which has caused nationwide panic, at first, afflicted the healthcare sector professionals with heavy physiological and psychological challenges that were represented by the unknown nature of the virus, fear of contracting the virus, stigmatization and conflict between family and professional obligations (Bizri et al. 2020). However, the COVID19 pandemic has also exposed the lives of university students to similar circumstances that have caused them severe distress, yet this population is usually disregarded even though such circumstances might negatively influence their assimilation and academic achievement. This condition will negatively impact learning thus disturbing the students' general psychological wellbeing by increasing the aversion of learning experiences and challenging their psychomotor focus (Rouadi and Anounti 2020). The results of this study showed that Lebanese university students are living high stressful conditions that relate to the pandemic and the consequential university closure and embargo. This was consistent with a previous study that was carried out during the times of Severe Acute Respiratory Syndrome (SARS) outbreak in 2003, and have shown that university students were susceptible to high levels of stress that were associated with fear of infection and distress during quarantine that is associated with confinement and anxiety that comes with learning challenges (Al-Rabiaah et al. 2020). Our results were also consistent with previous research that has also shown that university students and especially those who study health related majors such as nursing and medicine are inclined to be exposed to high stressful circumstances during such outbreaks, where they might be passing on some essential skills and modules that might not be replaceable (Husky et al. 2020). Another similar study was in line with our findings, where it has shown that female university students from non-health majors have displayed signs of high stress during the SARS outbreak, due to academic related issues (Brooks et al. 2020) while another study have shown 
that female undergraduate students had higher levels of anxiety due to fear of infection than male university students during the MERS-CoV outbreak (Saddik et al. 2020). Moreover, our study findings were in line with a previous research paper that have revealed that undergraduate medical and health sciences students have exhibited heightened emotional reactions to the outbreak during the SARS crisis, where high stress scores were recorded (Al-Rabiaah et al. 2020). Furthermore, our findings have highlighted that online learning experiences are posing high stressful environments and challenging demands to keep up with academic requirements. This is consistent with a previous research study that have shown that exclusive online learning experiences tend to have various drawbacks with regard to undergraduate students' learning outcomes as well as the psychological climates associated with that (Gillett-Swan 2017). As for the coping mechanisms of the students, the results of this study have shown that Lebanese undergraduates, have been using active oriented coping, where they are using discussion and expression of concerns as well as diversional activities to relieve the stress during COVID-19 quarantine. This was consistent with a previous study that have shown that university students tend to address their concerns when there are experience distressing events especially those relating to academic issues (Mundia and Shahrill 2018). The results of this study has also shown that some of the students are developing negative health habits as a form of stress relieve such as over eating and smoking. This is also consistent with previous research that have shown that there is a significant relationship between smoking and stress among university students (Kim 2019) and in line with another study that have shown that high stress levels among undergraduate students have gave rise to overeating and nutritional imbalances (AlJaber et al. 2019).

\section{Limitations}

The limitation of this study was that the researchers were not able to acquire data from more universities that have closed due to COVID-19 in other areas of Lebanon, which might have enriched the paper with more depth of perceptions.

\section{Conclusion}

The COVID-19 pandemic have afflicted many populations around the world including Lebanon which is simultaneously dealing with a crippling economic crisis. In the light of the outbreak, the government have imposed a nationwide quarantine which meant closing higher educational institutions, which rendered students learning through online portals and platforms. This study showed that Lebanese undergraduate students are being psychologically challenged by the elearning methodologies in order to continue their education and meet the university demands during the times of the pandemic, thus it would affect their learning and academic achievement if left untreated.

\section{Recommendations}

The researchers recommend higher educational institutions to recognize the students' experiences and employ more lenient policies in these difficult times, in order to facilitate the learning experience and safeguard the students' academic achievement, and more important their physical and psychological health. Health awareness campaigns should also be initiated by universities, which tackle the coping mechanisms and health habits needed to face the existing challenges. Further studies are recommended to integrate both quantitative and qualitative techniques to test the relationship between socioeconomic factors, familial and individual factors and student experiences during and after quarantine.

Acknowledgments The authors would like to acknowledge the efforts of the students who participated in the study, which enabled the publishing of this paper.

Data Availability The datasets generated during and/or analyzed during the current study are available from the corresponding author on reasonable request.

\section{Compliance with Ethical Standards}

Ethical Considerations The work described has been carried out in accordance with The Code of Ethics of the World Medical Association (Declaration of Helsinki) for experiments involving humans; Uniform Requirements for manuscripts submitted to Biomedical journals. Institutional Review Board was acquired from the university from which data was collected (IRB number: ECO-R-20).

Disclosure Statement On behalf of all authors, the corresponding author states that there is no conflict of interest.

\section{References}

AlJaber, M. I., Alwehaibi, A. I., Algaeed, H. A., Arafah, A. M., \& Binsebayel, O. A. (2019). Effect of academic stressors on eating habits among medical students in Riyadh, Saudi Arabia. Journal of family medicine and primary care, 8(2), 390-400. https://doi. org/10.4103/jfmpc.jfmpc_455_18.

Al-Rabiaah, A., Temsah, M. H., Al-Eyadhy, A. A., Hasan, G. M., AlZamil, F., Al-Subaie, S., et al. (2020). Middle East respiratory syndrome-Corona virus (MERS-CoV) associated stress among medical students at a university teaching hospital in Saudi Arabia. Journal of Infection and Public Health, 13, 687-691. https://doi.org/ 10.1016/j.jiph.2020.01.005.

Anney, V. N. (2014). Ensuring the quality of the findings of qualitative research: Looking at trustworthiness criteria.

Bizri, A. R., Khachfe, H. H., Fares, M. Y., \& Musharrafieh, U. (2020). COVID-19 pandemic: An insult over injury for Lebanon. Journal of Community Health, 1-7. 
Brooks, S. K., Webster, R. K., Smith, L. E., Woodland, L., Wessely, S., Greenberg, N., \& Rubin, G. J. (2020). The psychological impact of quarantine and how to reduce it: Rapid review of the evidence. The Lancet., 395, 912-920. https://doi.org/10.1016/S0140-6736(20) 30460-8.

Chen, Y., Peng, Y., Xu, H., \& O’Brien, W. H. (2018). Age differences in stress and coping: Problem-focused strategies mediate the relationship between age and positive affect. The International Journal of Aging and Human Development, 86(4), 347-363. https://doi.org/10. 1177/0091415017720890.

Corwin, Z. B., \& Clemens, R. F. (2020). Analyzing fieldnotes: A practical guide. In Handbook of qualitative research in education. Edward Elgar Publishing.

Crotty, M. (1998). The foundations of social research: Meaning and perspective in the research process. London: Sage.

ESCWA warns: more than half of Lebanon's population trapped in poverty. (2020). Retrieved 9 December 2020, from https://www. unescwa.org/news/Lebanon-poverty-2020

Etikan, I., Musa, S. A., \& Alkassim, R. S. (2016). Comparison of convenience sampling and purposive sampling. American Journal of Theoretical and Applied Statistics, 5(1), 1-4.

Gao, J., Zheng, P., Jia, Y., Chen, H., Mao, Y., Chen, S., Wang, Y., Fu, H., \& Dai, J. (2020). Mental health problems and social media exposure during COVID-19 outbreak. PLoS One, 15(4), e0231924. https:// doi.org/10.1371/journal.pone.0231924.

Gardner, P. J., \& Moallef, P. (2015). Psychological impact on SARS survivors: Critical review of the English language literature. Canadian Psychology/Psychologie Canadienne, 56(1), 123-135.

Gillett-Swan, J. (2017). The challenges of online learning: Supporting and engaging the isolated learner. Journal of Learning Design, 10(1), 20-30. https://doi.org/10.5204/jld.v9i3.293.

Hand, D. J. (2013). Qualitative inquiry in clinical and educational settings by Danica G. hays, Anneliese a. Singh. International Statistical Review, 81(1), 167-168.

Heffer, T., \& Willoughby, T. (2017). A count of coping strategies: A longitudinal study investigating an alternative method to understanding coping and adjustment. PLoS One, 12(10), e0186057. https://doi.org/10.1371/journal.pone.0186057.

Huang, L., Lei, W., Xu, F., Liu, H., \& Yu, L. (2020). Emotional responses and coping strategies in nurses and nursing students during Covid19 outbreak: A comparative study. PLoS One, 15(8), e0237303. https://doi.org/10.1101/2020.03.05.20031898.
Husky, M. M., Kovess-Masfety, V., \& Swendsen, J. D. (2020). Stress and anxiety among university students in France during Covid-19 mandatory confinement. Comprehensive Psychiatry, 152191.

Jaspal, R., Assi, M., \& Maatouk, I. (2020). Potential impact of the COVID-19 pandemic on mental health outcomes in societies with economic and political instability: Case of Lebanon. Mental Health Review Journal.

Khalid, I., Khalid, T. J., Qabajah, M. R., Barnard, A. G., \& Qushmaq, I. A. (2016). Healthcare workers emotions, perceived stressors and coping strategies during a MERS-CoV outbreak. Clinical Medicine \& Research, 14(1), 7-14. https://doi.org/10.3121/cmr. 2016.1303 .

Kim, H. J. (2019). Smoking behavior, smoking motivation, stress, physical condition and health promotion behavior of college students with no smoking intention. Medico Legal Update, 19(2), 635-640. https://doi.org/10.15268/ksim.2019.7.3.189.

Mundia, L., \& Shahrill, M. (2018). The impact of coping and helpseeking on university students' academic achievements.

Richards, K. (2003). Qualitative inquiry in TESOL. New York: Springer.

Rouadi, N. E., \& Anouti, M. F. (2020). The online learning experiment in the intermediate and secondary schools in Lebanon during the coronavirus (COVID-19) crisis. Online learning, 7(7).

Saddik, B., Hussein, A., Sharif-Askari, F. S., Kheder, W., Temsah, M. H., Koutaich, R. A., ... \& Halwani, R. (2020). Increased levels of anxiety among medical and non-medical university students during the COVID-19 pandemic in the United Arab Emirates. medRxiv.

Schmitt, F. (2017). Social epistemology. The Blackwell guide to epistemology, 354-382.

Shosha, G. A. (2012). Employment of Colaizzi's strategy in descriptive phenomenology: A reflection of a researcher. European Scientific Journal, 8(27).

Speziale, H. S., Streubert, H. J., \& Carpenter, D. R. (2011). Qualitative research in nursing: Advancing the humanistic imperative. Philadelphia: Lippincott Williams \& Wilkins.

Van Nguyen, D., Pham, G. H., \& Nguyen, D. N. (2020). Impact of the Covid-19 pandemic on perceptions and behaviors of university students in Vietnam. Data in Brief, 31, 105880.

Publisher's Note Springer Nature remains neutral with regard to jurisdictional claims in published maps and institutional affiliations. 